\title{
EXPLORING THE ECOLOGICAL FOUNDATIONS OF MEMORY IN PSYCHOTHERAPY: INTERPERSONAL AFFORDANCE, PERCEPTION, AND RECOLLECTION IN REAL TIME
}

\author{
Steven J. Trierweiler \\ University of Michigan \\ Cleary M. Donovan \\ University Associates in Psychology
}

\begin{abstract}
Recent evidence suggests that memory narratives are fallible cognitive and social constructions. Yet, the literature lacks specific frameworks for guiding clinicians' inquiry into such narratives. We propose one such framework that focuses on interpersonal memories. The model, which is based on Gibson's Theory of Perception as applied to the interpersonal domain, seeks a detailed database from which higher level clinical inferences can be derived. Case material is used to illustrate its application. The model is discussed in relation to recent research and controversy about psychotherapeutic memory, and a stance clinicians might take toward memory phenomena.
\end{abstract}

Memories of specific interpersonal events in a client's life are the grist for the psychotherapeutic mill. Typically, these memories take the form of narratives (Bonanno, 1990; Bruner, 1986; Polkinghorne, 1988; Sarbin, 1986; Spence, 1982) referencing interactions with significant others, usually loved ones, in the recent or distant past. As they emerge in psychotherapeutic conversations, such events are commonly understood in very limited ways and they have seldom been thought through in detail. Clients usually simply take them for granted as a part of their life story. Brewer (1986) calls memories of this sort personal memories, in that they involve the recollection of particular episodes in the

Correspondence should be addressed to Steven J. Tricrweiler, Department of Psychology, University of Michigan, 580 Union Drive, Ann Arbor, MI 48109-1346. 
individual's life. He notes that they: typically involve a sense of reliving the personal experience of the episode, almost always involve visual imagery, seem to reference a specific location in time and space, and are accepted by the person to be an accurate record of the experience. Such memories, in referencing single episodes, are distinguishable from more generic autobiographic knowledge (e.g., "I grew up in a small town") or schematized events based on repetition of an event pattern with minor variation (e.g., "I eat cereal for breakfast."). In this paper interpersonal memories refer to personal memories with interpersonal content.

The problem for the clinician has long been how to understand interpersonal memories theoretically and practically. As dramatically illustrated in the recent controversy about Freud's views of incest memories (Masson, 1984), this problem generally reduces to questions about how to ascribe truth value to memory narratives: are they representations of the realities of past episodes, distortions of these realities, productions of fantasy, or fallible reconstructions? Should the clinician focus on the manner in which the narrative is constructed or on the historical referent of the narrative? Whereas the position a clinician takes with respect to this epistemological problem can greatly influence the course of treatment (e.g., Loftus, 1993), specific practical guidance is rarely available. We address this problem by extending work begun by Safran and Greenberg (1988) in bringing together three theoretical lines: ecological perception theory (Gibson, 1966, 1979, 1986), current cognitive theory (e.g., Neisser, 1976), and an interpersonal approach to therapy (e.g., Safran \& Segal, 1990; Sullivan, 1953). In so doing we develop a guiding conceptual framework for the clinical investigation of interpersonal memories that both has a solid theoretical underpinning and clear practical applications.

\section{RECENT CLINICAL FORMULATIONS OF MEMORY}

In the past decade clinicians have paid increasing attention to the implications of cognitive psychology for clinical practice (e.g., Dickman \& Sechrest, 1985; Guidano \& Liotti, 1983; Mahoney, 1985; Mahoney \& Gabriel, 1987; Turk \& Salovey, 1985). Epistemological issues concerning memory narratives are central to this work. 'The overarching message has been that memory narratives are, at best, fallible representations of life episodes (e.g., Dickman \& Sechrest, 1985; Orne, Whitehouse, Dinges, \& Orne, 1988). Therefore, clinicians have focused almost exclusively on cognitive structure and process, attending more to how memory narratives are constructed than to the historical events they reference. New cognitive tools for analyzing memories have been emphasized, such as schema theory (Neisser, 1976; Safran \& Greenberg, 1988; Turk \& Salovey, 1985), imagery (e.g., Klinger, 1978), and descriptions of cognitive and social construction processes (Gergen, 1985; Guidano \& Liotti, 1983). Moreover, there has been widespread acceptance of the notion, rooted in the sociology of knowledge (e.g., Berger \& Luckman, 1966; Mannheim, 1936), that scientific and clinical theories, are about, and are themselves, narrative constructions (e.g., Bruner, 1986; Gergen, 1985; Sarbin, 1986) wherein meaning is socially, rather than objectively, legitimated. This thinking has encouraged clinicians to avoid viewing memories simply in terms of historical truth.

More recently, consistent with a longstanding tradition linking interpersonal and cognitive perspectives (e.g., Carson, 1969; Sullivan, 1953), theorists have paid greater attention to interpersonal process than in the past. Bonanno (1990), for example, draws on Spence's (1982) distinction between narrative truth and historical truth to discuss how memory narratives can be understood as representations of important interpersonal themes in the individual's life, thereby suggesting that historical accuracy is less relevant than traditionally thought.

Even if memory narratives are constructions affected by cognitive and social processes, 
as recent literature suggests, there remains the problem of how to respond to this material. When is a memory understood well enough? What aspects of the material should be taken as given, and what should be dealt with as interpreted? If all is interpreted, is there any meaningful sense in which the clinician can pursue the historical basis of the memory? Several authors have discussed the clinical consequences of this issuc. Coyne and Gotlib $(1983,1986)$ caution that failure to acknowledge the accuracy of certain interpretations of interpersonal events may lead to difficulties in helping clients change problematic cognitions. Others (Rice, 1984; Safran \& Greenberg, 1984; Safran \& Segal, 1990) take an intermediate position on the epistemological issue, suggesting that investigation of memories can reveal contextual and emotional information relevant to interpersonal process, in addition to interpersonal themes, that may have been present in the past and that might otherwise have been obscured in the narrative. Empirical evidence concerning the incidence of childhood physical and sexual abuse (Finkelhor, 1979), and the subsequent renewed interest in psychological trauma (e.g., van der Kolk, 1988) has alerted clinicians to the serious consequences of not accepting the truth value of certain memories. However, in reviewing the enormous impact that the reemergence of trauma theory has had over the past decade, Loftus (1993) has expressed concern about the trend for clinicians, the public, and the legal system to over-identify and adjudicate sexual abuse based on the evidence of so-called repressed memories. Particularly compelling is the sizable body of empirical evidence suggesting that memories can be distorted and modified by a variety of situations, including the ways questions are asked about the event. This raises serious doubt about the extent to which event memory narratives represent authentic circumstances in an individual's life. Although caution is required in making causal attributions based solely on the evidence of a client's memory-particularly in the legal context - the regularity with which clinicians deal with memories of all kinds, from the mundane to the dramatic, is unlikely to change in the near term. A specific operational framework is needed, beyond informal clinical lore, for interpreting how a specific narrative comes into the therapy and for dealing with fallible information in the assessment of historical events and cognitive structures.

In considering this problem, it is important to maintain distinctions among: (a) the range of concerns identified in the memory literature that can render any particular memory narrative equivocal; (b) the adequacy of implicit models of interpersonal memories that designate what, in principle, would be needed for them to be maximally identified; (c) the technical problems various theoretical and empirical concerns raise for clinical inquiry. The literature on clinical memory has been much more strongly focused on (a), and has virtually ignored (b) and (c). Indeed, there have been no explicit attempts to identify the general properties of optimally informative memory narratives for different purposes. Rather, we have been mired in various versions of a long standing controversy between viewpoints that posit some vague notion of objective reality, versus those rejecting any possibility of coordination between a memory narrative and events in the past. We believe this debate has developed to the point where more integrative alternatives are possible, although the problem becomes more complex than as originally framed. Next we address such an integration by proposing a heuristic tool that is consistent both with the literature on memory and with the realities clinicians and clients face in a psychotherapeutic inquiry.

\section{THE NEED TO EXAMINE THE PERCEPTIONS UNDERLYING INTERPERSONAL MEMORIES}

Because most memory narratives are naturally abstract and imprecise, one approach is to make them more concrete. This thinking is consistent with a long tradition in the clinical 
literature supporting the exploration of memory detail (e.g., Loewald, 1976; MacKinnon \& Michels, 1971; Safran \& Segal, 1990; Sullivan, 1953). Schachtel (1949), for example, citing Proust's (see Proust, 1982) famous portrayal of childhood events evoked by the taste of a madeleine (an almond cookie), noted how recollections of the concrete trifles of childhood experience often evoke the larger surrounding emotional context as viewed from an adult perspective. Unlike Freud (1899/1989), who felt that such memories were a "screen" or concealment for underlying conflictual emotional states, Schachtel believed that the emotional conditions actually coexisting with the thing remembered could be discovered by careful inquiry. Concrete memories seemed to involve a condensation of emotional conditions existing in the past but not describable due to limitations of the client's development and the cultural context of the remembered event.

In addition, there are two lines of empirical support in recent cognitive literature suggesting that concretizing a memory might be a productive line of inquiry. First, in contrast to the literature cited earlier, it has been shown that individuals actually can attain higher levels of accuracy in eyewitness memories if they focus on the context and concrete details of an event (Geiselman, Fisher, MacKinnon, \& Holland, 1985; Malpass \& Devine, 1981). This is precisely the kind of detail found to be problematically identified in the eyewitness paradigm discussed by Loftus (1993). Second, Bucci's (1989) work, based on Paivio's (1990) memory model, suggests that clinical interpretations that include more concrete life details are more efficacious because they are more richly connected with the client's experience. Nonetheless, despite these promising demonstrations, the work described by Loftus (1993) suggests that the fact of narrative detail, in itself, is insufficient grounds for establishing the truth value of the event described: such details may also be subject to distortions of fantasy, the context of the memory, and so on. Thus, a conceptual tool for analyzing memories must facilitate an understanding of both the details, and the various impressionistic and inferential observations one finds in a psychotherapeutic memory narrative.

To this end, our model pushes the notion of exploring the concrete to its logical extreme by focusing on the revelation of directly experienced perceptual detail. It is guided by a more precise conceptualization of interpersonal perception than has existed to date. The model is based on Gibson's $(1966,1979,1986)$ ecological model of perception, and a representation of the development and transformation of memories in real time. We use the terminology "real time" to emphasize the need for clinicians to attend carefully to the continuity, order, and directionality of time in the physical world (Hawking, 1988), even though there will be practical limitations on the extent to which this is possible. It is equivalent to the notion of proper time in physics (Bynum, Browne, \& Porter, 1981). Proper time refers to an interval in the history of a material point as measured by an ideal clock moving along with the point. The measurement of proper time is invariant in space-time because all such clocks, moving along with the point, would achieve the same result. We are using a strict physical conception of time to emphasize that memories ultimately reference physical and subjective events that emerge within the continuous stream of a person's experience. These events have invariant order and are, in a strict sense, not repeatable within the life span, even though narratives will only broadly reflect this structure. In contrast to more informally produced narratives, our formulation emphasizes the importance of detailed descriptions of basic perceptual information (e.g., what is being looked at moment to moment) and feeling states (e.g., tension, confusion, boredom, and so on) as they occurred. In effect, we seek a more fine-grained examination of the time stream (smaller time units) than one usually finds in narrative descriptions. We then consider these detailed events in light of the various interpersonal contexts for remembering occurring throughout an individual's life. 
This approach is consistent with recent views of memory narratives as complex social and cognitive constructions rather than as definitive portrayals. Nonetheless, we argue that some information conveyed in a memory narrative is more grounded in direct experience than other information. As such, specific measures can be taken to enhance one's grasp of this groundedncss without naivcly assuming that all narrativcs arc definitive representations of authentic events, or conversely, that all narratives are equivalently distant from material experience. Our goal is to present one approach to the memory problem that we have found to enhance communication with clients and to make descriptions of historical events more precise.

The exposition that follows consists of: (a) an overview of the guiding elements of Gibson's ecological theory of perception, (b) a discussion of its specific application in the domain of interpersonal experience, (c) a discussion of the development of a memory narrative in real time that is implied by the thenry, (d) clinical case illustrations, and finally (e) a general discussion of how this approach relates to various issues in the clinical memory literature.

\section{GIBSON'S ECOLOGICAL APPROACH TO PERCEPTION}

\section{Why Gibson?}

Gibson's $(1966,1979,1986)$ theory of perception is a particularly fitting model for interpreting perception in the interpersonal domain where events have considerable temporal extension. Traditionally, perception has been cast in terms either of objective properties of stimuli or of cognitive structures guiding attention and perception, but rarely are the two positions integrated. Furthermore, while time might be recognized as relevant in traditional theories, the explicit impact of the time's directional arrow is often ignored. In contrast, the Gibsonian approach avoids such one-sided, static formulations by explicitly placing the relationship between the perceiver and the perceived in dynamic historical perspective.

\section{Perception in Ecological Context}

The Gibsonian, or "ecological," position takes the entire matrix of the person embedded within physical space-time context into account. Gibson labored to show that perception involves the resonance to information that is in the world, not in the head (Gibson, 1979, 1986; Reed, 1988). Thus, although higher cognitive processes are important, they are not needed for a theory of perception. But, for Gibson, this was not equivalent to an endorsement of stimulus theory, where the material aspects of the world are presumed to have normative properties perceptually available to all. Rather, he viewed perception as a function of the dynamic interplay between an acting perceiver and the thing perceived in an ongoing stream of time and motion. He developed the notion of direct perception, an active process in which the information registered is influenced by both its availability in the physical world and the goals and actions of the perceiver.

McArthur and Baron (1983) have discussed how this position can be fruitfully applied to social and, hence, interpersonal perception. Interpersonal events are dynamic, providing temporally organized information to the individual in the ways things remain the same with the other person (structural invariants) and in the ways they changc and develop (transformational invariants). Gibson provides a tool for conceptualizing how information is perceived in the concept of affordance. This concept refers to information in the perceptual field that is relevant to the perceiver's action and goals; affordances are "action possibilities provided by an object" (McArthur \& Baron, 1983, p. 217). For 
example, a mother who feigns incompetence in catching a baseball is affording the possibility of a successful demonstration of skill, and hence enhanced confidence, for her son as he rushes to catch it before her. The ecological perspective forces us to consider the affordance possibilities of a relatively unique interpersonal field moving in space and time without assuming an objective stimulus or completely constructive operations. As McArthur and Baron point out, because affordances depend on the observer's current actions and goals, they can change with different situations. With time, an observer can learn to attune to different affordances, even in seemingly identical circumstances. Nonetheless, from the ecological perspective, there must be supportive information available in the invariant properties of the perceptual field, before such shifts in attention are possible. This has considerable implication for our conception of interpersonal events. If the mother in our example continued to feign incompetence with a baseball (a structural invariant) as her child hecame more familiar with his skills, the boy's perceptions of similar actions may change; her action might come to afford more negative perceptions to her son, such as frustration with the difficulty in involving her in a game of catch (a description of a response to an affordance). But her truc skills would not be perceived unless her feigning action is somehow revealed to him (e.g., she catches car keys with finesse at some later time - a transformational invariant). In turn, he would be unable to perceive her intention in the feigning action, an act of maternal kindness, without significant development of his skills at interpersonal perception.

\section{Interpersonal Perception as the Historical Foundation of Interpersonal Memory}

From this perspective, the descriptions of events offered in most memory narratives are insufficient in that they rarely offer precise descriptions of the affordance structure operating in the direct perception of the event. Yet, memories for events that had palpable existence are rooted in basic perceptual processes as they unfold in real time, even if this can be difficult to assess. For example, to say that one remembers someone in a room is not to say how this presence was perceived. Instead, one may actually have a visual image in mind in describing the presence, or something entirely different, such as hearing the person move while staring at a wall.

To summarize, the Gibsonian position, in pointing to the effects of time on perception identifies several properties of events that are highly relevant to the retrospective examination of interpersonal phenomena. First, information is neither the objective stimulus of traditional perception theory, nor is it completely a result of cognitive processing. Rather, information is locally specified in space and time in the affordance structure of the event. Second, information attunement is a real time operation dependent on, and to some extent bounded by, both properties of the event and properties of the perceiver. Third, any subsequent interpretations of the event, including all memorial recunstructions, however abstract, find their origins in one or more perceived affordance structures locatable in space and time. As a result, the conceptual meanings expressed in subsequent memory narratives can be thought to have a foundation in the perceptual meaning of the original event referenced (cf. Shaw \& Hazelett, 1986). A notion of historical truth can be meaningful in this theory but only in relation to specified properties of an observer and the affordance possibilities of the ecological field existing in space and time. The problem for the clinician becomes one of discerning the affordance structure of some distal event based solely on a proximal verbal interaction with the client.

\section{Implications for Clinical Inquiry}

In this view, memory narratives are linguistic and interpersonal events in their own right involving some level of achievement in communicating about the affordance structure of 
interpersonal events directly perceived in the past, and the understanding of those events that has evolved over the course of time since they took place. The reality they are presumed to reference is a perceptual reality that is limited by the ecological conditions prevailing at the time of the event; by post hoc cognitive and emotional processes, including transferential processes in therapy (e.g., Gill, 1982); and by other events not mentioned initially, such as reading a book that makes one think of the past in a different way (e.g.; Loftus, 1993). Thus, it is not a matter of the memory being fallible with respect to an external objective standard, nor of it being completely constructed, though both perspectives are useful in different contexts. Rather, in the context of the therapeutic focus on the individual's own perceptual stream, there is no right or wrong, just various levels of achievement with respect to understanding, sharing, and integrating into one's life story a real event, located in space and time, via linguistic representation. By implication, some portion of a memory narrative is a purely linguistic interpretation of the event, and some portion maps information directly perceived in the past. The problem for the clinician becomes one of using narrative evidence to speculate about the perceptual course of interpersonal events in the past, and in so doing, to gain a better understanding of the prevailing ecological conditions referenced in the memory narrative. The point here is that all memory narratives, save perhaps those produced by a client who is purposefully lying, reference some aspect of the client's experience - though that experience need not be of the event apparently referenced in the narrative - and in this sense the narrative is not right or wrong. Clinicians, on the other hand, as interpreters of this material, may erroneously jump to conclusions about the nature of events based on insufficient data or attend only to cognitive or social constructive operations and ignore the material and temporal constraints of the experience stream. In the next section, we present a model to facilitate an inquiry into interpersonal memories that is compatible with the real time complexity of events.

\title{
A MODEL FOR EXPLORING THE ECOLOGICAL FOUNDATIONS OF INTERPERSONAL MEMORY
}

To illustrate the application of these ideas in a clinical context, consider a fairly typical example of an interpersonal memory embedded in a larger conversation. This memory emerged over several discussions with a 28 -year-old man about his unhappiness at work.

\begin{abstract}
He offered an example from the past of his father "acting crazy." He described how he had returned home with his father's pickup truck from transporting goods to his college apartment. In so doing, he mistakenly placed a paint can in the back of the truck in such a way that it spilled. His father, always a stickler for responsible action, flew into a rage and began hastily cleaning the pickup box while screaming uncontrollably at his son. The young man described the mixture of fear, anger, and humiliation that accompanied his father's "crazy" behavior, summarized in the phrase "Get me out of here."
\end{abstract}

Clinicians will recognize linkages between the recollection, the work situation, and even the therapeutic relationship itself. How can one examine the memory further? What follows is distinctive from traditional views of memory in two ways. First, ecological theory's demands for strict representation of real time perceptual moments extends more deeply into the realm of sensory information than traditional approaches. Thus, a typical event narrative is not adequate from this perspective. Second, interpersonal events, and interpretations of those events, are seen to unfold in strict temporal order, the analysis of which is crucial to understanding how they inform interpersonal experience in the pres- 
ent. As we will show, the examination of perceptual and interpersonal detail demanded by the model has important clinical payoff.

\section{INTERPERSONAL AFFORDANCE, PERCEPTION, AND RECOLLECTION IN REAL TIME}

\section{Overview: The Omniscient Perspective}

In considering how ecological theory's attention to time and motion informs remembering in the interpersonal domain, it is useful to imagine the perspective of an omniscient observer moving along with a client throughout his/her life span. Such an observer would have a fine grained awareness of the enduring behavioral and subjective qualities (invariants) of the client's interactions and expertise in linking this material to later interpretations. This observer might portray the thousands of interpersonal interactions the client engages in as regions on a timeline in a two-dimensional space-time representation. In this picture, an interaction could be represented by the convergence along the space dimension of the client's timeline with that of another. Such convergences would extend along the time dimension until the particular interaction was over and the individuals left one another's presence, perhaps to converge again at some later time. Among other things this representation would reveal that the specific events referenced in a memory narrative occupy a unique location on the two-dimensional space-time map. Additionally, the timeline would show the larger temporal context within which the event and its remembering occurred, and any other events, such as conversations with others, that reference the event. It would show that while interpretations of the event change with successive recollections, the event itself cannot be changed or reviewed because of its unique place back down the timeline. At a more microscopic level, it would reveal the precise details of the perceptions of each act as the event unfolded, as well as information about how the context of the interaction affected the event. Some of this material would not be available for self-report to the actors themselves even if the event were clearly remembered (Nisbett \& Wilson, 1977). If the observer were skilled at grasping how interpretations the person makes relate to the specifics of an event as perceived, then he/ she could generate a thorough understanding of how the client uses language and other events in life to interpret the past. (One would hope therapists would approximate such skilled meta observers were they able to review significant interpersonal events.)

Figure 1 is a schematic representation of a portion of such a space-time interaction map pertaining to the temporal ecology of one memory narrative. In the figure, time proceeds from left to right with the remembered event occupying the left side of the figure, and the therapy session in which it is recollected, the right side. The timeline for the client is the top portion of the figure, while portions of the timelines for other and the therapist are designated at the bottom. In this model, interpersonal memories identify the conjunction of two such timelines; client and other (other can be several others and social aggregates as well). The conjunction of these lines is typically a function of physical proximity in space and time, as shown by the lines coming together and moving apart as time proceeds from left to right. Each actor is represented by two lines identifying that actor's continuous physical and subjective presences in time. Physical presence refers to all aspects of the physical being of the actor, including structure, appearance, motion, and overt verbal and nonverbal expression. Subjective presence refers to conscious subjective states that could, in principal, be verbalizable if the individual stopped and did so (e.g., Ericsson \& Simon, 1984).

This model shows that the act of generating a memory narrative references at least 


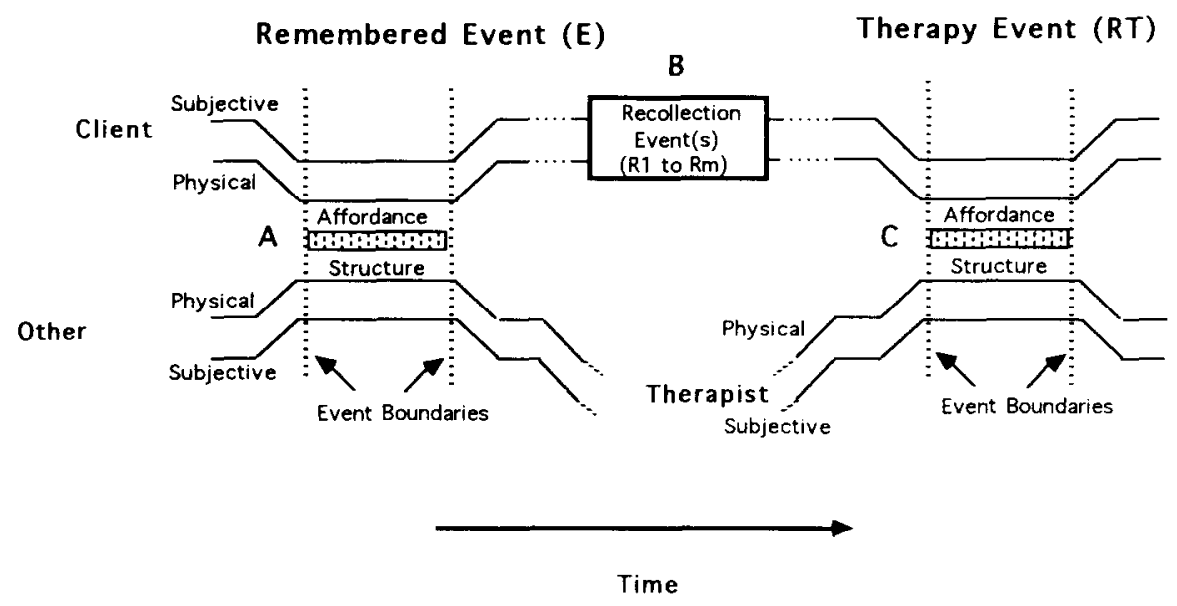

FIGURE 1. A representation of the temporal lines of affordance, perception, and recollection of an interpersonal event in a therapy session.

three sources of information: the affordance structure of the remembered event as it occurred in time (area A), one or more recollection events that might have occurred between the remembered event and the production of the narrative (area $B$ ), and the affordance structure of the therapy session in which the narrative is generated (area $C$ ). It outlines what a clinician might wish to know under ideal circumstances and reveals several important constraints on interpersonal perception, when viewed from an ecological perspective, that should be kept in mind in examining memory narratives.

\section{Interpersonal Perception is Continuous and Ordered}

First note that continuous lines are used to depict the subjective and physical presence of each individual. This emphasizes that a person's physical being and perception are continuous and ordered in time despite our tendency to speak of events as discrete entities, often imprecisely placed in the time stream (Friedman, 1993; Miller \& Johnson-Laird, 1976). Both the client and the other entered the remembered interaction (area $\mathrm{A}$ in Fig. 1, the segment of the timelines between the event boundaries) on their own subjective timelines, each uniquely representing their previous direct experience of other situations and of one another. Depending on their skill as observers and the affordability of particular states, both the physical and subjective presences of each were afforded to the other, along with the sociocultural and temporal context of the event. In the Gibsonian model this would occur via structural and transformational invariants noticeable in their history of interaction. For example, if the young man saw his father appearing "crazy" as he approached (a possible reference to an affordance - further detail is needed for a sensory level description), this determination may, or may not, have been revealed in a physical expression on the son's face that, in turn, afforded some meaning to the father. Moreover, the direct perception of the event occurred within a specific space-time context that may have had important implications for what was perceived and how it was interpreted and recollected. Thus, the father may indeed have been perturbed with the son because of other recent events suggesting the son's irresponsibility. However, his demeanor, rather than leading his son to an awareness of the problem, may have afforded certain actions, such as 
avoidant noncompliance, but not others, such as apologizing. In this way the affordance concept draws our attention to the experience-action possibilities of a particular interpersonal moment; such space-time localized events may involve rather specific and in some cases unique affordances for each participant, and these affordances constrain their actions, both then and later, and any later interpretations they generate.

The event can be thought of in terms of large or small time units (see Ginsburg \& Smith, 1993; Newtson, Engquist, \& Bois, 1977). The notion of affordance requires that there be invariance in the informational properties of the situation across time. Therefore, because time is continuous and ordered, the significant time units represented in a memory narrative would need to be much smaller than they are typically if they are to precisely capture the relationship between various narrative elements and perceptual memory. In Fig. 1, this is indicated by the segmented bars of the affordance structures identified. Each segment represents a hypothetical statement about something recognized in the time stream. If it were possible to get descriptions of what each actor is thinking and perceiving moment to moment, as in thinking aloud procedures commonly used in cognition laboratories (e.g., Ericsson \& Simon, 1984), then we would begin to approximate a definitive accounting of the perceptual material that constrains what can be said later about the event. Even more, one could imagine a videotape taken from the perspective of each actor, coordinated with an ongoing description of what is being perceived, as being a still closer representation of this material. All the details of such a sequence might not be of interest to a clinician and certainly an individual's perspective does not capture the whole story of an event. Nonetheless, as this formulation makes clear, such detail exists necessarily in the flow of time, whether we successfully access it or not, and it may or may not be represented in a narrative depending on the client's ability and motivation to do so.

Finally, the emphasis on continuity and order in the model reveals an ecological reality, directly germane to understanding a memory narrative, that the client could not possibly access and that will remain obscure if the clinician only investigates contemporary subjectivity in the client's own terms - as is often seen as the sine qua non of good therapy. This reality, which is captured in the perspective of the omniscient observer, is centered in area $\mathrm{A}$ in Fig. 1, the temporal locus of affordance of the remembered event, where the client perceives the other event and the other perceives the client event. The extent to which this larger perspective could be perceived and interpreted at this time, depended on the client's developmental level, observational skills, and perceptual learning in the interpersonal realm. Moreover, in the moment-to-moment stream of time, it depended on such mundane but ultimately determinative, phenomena as where attention was focused, as in eyes looking to the floor or directly at the face of the other. We believe this perspective on the event, as placed within a continuous and ordered time stream, needs greater attention in memory inquiry.

Before going on it is important to note that while Gibson $(1979,1986)$ was clear that social information is directly afforded in temporally extended social encounters, and there is data bearing on this matter (e.g., Runeson \& Frykholm, 1983), he did not address the issue of the perception of subjectivity directly (cf. Heider, 1958). It is likely that apprehension of subjectivity involves real time cognitive recognition processes (Neisser, 1991; Trierweiler, 1984) - as in the recognition of an instance of a linguistic category such as "disrespect" - as well as direct perception and retrospective attribution processes. Nonetheless, the point here is that both direct perception and recognition operate to some extent within a real time context, and therefore, they are both grounded in the informational properties of the available affordance structure. We argue that knowledge of this affordance structure is essential to adequate understanding of all higher level interpretations, including ongoing recognition processes. 


\section{Event Boundaries May be Unclear}

In addition to ambiguities in most narratives with respect to the microscopic details of interpersonal perception, there are ambiguities with respect to the larger event boundaries themselves. As noted above, event narratives imply temporal boundaries that are as often the result of linguistic convention as they are physical realities, even though perception is continuous (Miller \& Johnson-Laird, 1976). This practical bounding, while useful for communication, can give events an objective character that belies their underlying real time complexity. Ecological theory cautions us that the perceptual underpinnings of an event may not be well represented by linguistic convenience. To the extent perceptions of an event, as they were ordered in real time, were dependent on some prior experience of one or both actors, the temporal event boundaries initially revealed may be misleading. This is reflected in the use of dotted lines in Fig. 1. It suggests that clinicians would do well to stay open to the possibility that relevant event boundaries extend further into the past, and-for understanding how the narrative is framed (see below) - into the future, than may be initially apparent.

\section{Interpersonal Perception is Nonrepeatable}

Ecological theory makes clear how interpersonal perception is similar to, and different from, object perception, thereby revealing our dependence on language in interpreting the interpersonal realm. Whereas most object perceptions can be repeated in virtually isomorphic fashion - in effect making the perspective of an omniscient observer irrelevant to a basic understanding of the object-interpersonal events are strictly nonrepeatable and therefore they are often strictly personal (or intersubjective in a very limited sense). In the interpersonal context, time places severe limitations on the apprehension of information potentially afforded by the other, making it difficult to analyze the alternative possibilities an ambiguous interpersonal situation might present. The result is great potential for incomplete registration, and/or over generalization of available information (as in Neisser's, 1976 schema theory), especially given developmental limitations and the emotional tone of the event. In addition, opportunities for sharing perceptions with others for purposes of consensual validation are inherently limited; several instances of recollection and interpretation may occur before a directly perceived event finally emerges a therapy narrative, often years after the fact.

\section{Memory Narratives are Affected by Intervening Events}

Because interpersonal events are largely nonrepeatable, they are often best comprehended after they have occurred (e.g., Heider, 1958), and recollections are the only means for event analysis and interpretation. Area B of Fig. 1 represents one or more conscious recollection events. Shortly after the event, the young man in our clinical vignette may have thought to himself "What's the matter with my father? He's crazy.," and many other things, while engaging in actions like crying, pouting, angry displays, and so on. Such reflections are limited by the competency level of the individual and are highly dependent on language skills (e.g., Nelson, 1993). For example, the son may not notice, as would an omniscient observer, that the father came into the situation grouchy and preoccupied with some earlier error of his own, and in the absence of this information, the son may have had no alternative but to take his father's manner only as a comment on himself.

In effect, each episode of conscious recollection involves (a) the directly perceived, episodic elements of the event, as recollected and (b) any linguistic interpretations generated during and after the event. Still further interpretation is possible during each of these 
recollections. It is useful to think of them as directly perceived internal events tied to the ongoing perception of the external world. Thus, if the son has gained new information (e.g., dad has an alcohol problem), or new interpretive skills (e.g., recognition that dad may be upset at himself for not raising the boy right), then new interpretations of the event are possible. Furthermore, if the recollection coincides with conversations with others, say friends, then these may also contribute to a revised memory. Cognitive and object relations based theories posit cognitive and emotional reasons that certain problematic views of situations are maintained (Safran \& Segal, 1990; Westen, 1991). The ecological perspective adds a question about how such viewpoints are maintained in the context of the perceptual realities of events and whether they involve selection and/or distortion of information as the event unfolds, or after in reflective interpretation.

\section{Memory Narratives are Affected by the Interpersonal Circumstances Surrounding Their Production}

At area (C), the event is finally recollected in therapy, a setting where it can be analyzed systematically with the help of an expert. This recollection can involve both episodic and linguistic elements from the event itself and all previous recollections, as well as something new, the directly perceived aspects of the context of therapy. One important function of this therapeutic context is to facilitate attention to problematic event perceptions and interpretations thereby yielding more complete and realistic event narratives.

This section of the model merits special attention in that all the processes described thus far are operative within the immediate context of the therapy. Interpersonal approaches have assumed that the relationship with the therapist influences both the production and content of memory narratives (e.g., Carson, 1969; Safran \& Segal, 1990; Sullivan, 1953). In expanding this view, our model suggests that clinicians would benefit from careful reconstruction of even recent interpersonal events, within and proximal to the therapy, as well as more temporally remote events. Some interpersonal memories might be state dependent productions (e.g., Bower, 1981), where interpersonal conditions existing in the therapy lead to selective recall and description of past events.

This has important implications for the recent controversy about therapeutic memory. In particular, this view demands a therapeutic stance characterized by openness to elaboration of the narrative and active attention to the inherent uncertainty pervading all interpretation of remembered experience. For example, what is the impact of a client percciving the thcrapist to bc most intcrestcd in particular forms of information, such as dreams or abuse memories? This might be a situation where the influences that worry Loftus are operative, as the client strives to cooperate with, or to resist, the therapist's apparent interest. In contrast, if the intention of the therapist is to follow the model, directed as it is toward detailed elaboration of how a particular narrative relates to other narratives in the person's life-including narrative about recent moments in the therapy - then such influences are less likely to perniciously affect the client's understanding. At a still deeper level, transference and countertransference processes can be understood concretely in terms of the direct perception of the therapy event. Of course, clients can still fabricate and distort events, and therapists will continue to display interest, but there will be greater opportunity for both to understand the source and meaning of such distortions (or poorly understood elaboration) than typically exists in informal narratives. This is particularly true for the problematic narratives thought of as detailed, as in the eyewitness literature (Loftus, 1993) but that are interpreted separately from the interpersonal relationships that influence them. 


\section{The Event Information Universe and Its Interpretation in Real Time}

Before going on to some case illustrations, it is important to conceptualize, with greater precision, the information existing at the time of an event and of how this information comes to be represented later in a memory narrative. The model suggests that there are three possible categories of information available for linking a narrative to an event:

The Realized Affordance Structure of the Event. The realized affordance structure is what the client experienced directly; it involves information directly afforded about the physical and subjective presences of self, other, and context as the event unfolded. This is the type of information typically referenced by clients as they attempt to provide details about events in the past.

Recollection Information About the Event. This is information originating in the various recollections of the event, including both interpretations of the event and linguistic and episodic associations emergent in each recollection. It also includes information about the recollection events themselves that might pertain to one's understanding of the original event.

The Potential Affordance Structure of the Event. The potential affordance structure is a superset for the realized affordance structure. It includes unperceived information that would exist to an omniscient observer had one been present as the event unfolded. (Note that this is not necessarily a therapist's eye view, via some theoretical account, because the low level information available to an omniscient observer can only be approximated.) This hypothetical observer would have a more complete "data set," available for a variety of interpretive schemes, including psychological theory, than could either actor, even in principle.

Ideally, we would know how each of these categories of information operates in the narrative construction process. Unfortunately, it is rarely possible to achieve this level of comprehension. It is important that clinicians be aware of the material restrictions, implied by the model, that can limit our understanding of how a client's particular interpretations might have developed.

\section{Conceptualizing Affordance, Perception, and Recollection Using Set Theory}

The informational structure referenced in a memory narrative can be formally elaborated using tools from set theory. The first step is to conceptualize the potential affordance structure of the event as the universe of information that would, in principle, have been directly afforded to a hypothetical omniscient observer. If we allow that such an expert perspective would approximate a reasonably definitive account of the event, then let the information so obtained constitute the universe, $U$. Conceptually, $U$ is the hypothetical class of directly affordable information about the event that includes only low level descriptions of hasic actions, subjective states of each actor, and the context in which the event emerges in time. The temporal event boundaries would extend as far back from the time of the event as needed to grasp the information affordable in the event. Thus, for example, the assertive behavior of an actor may include some aspect of the individual's prior history of skill development in this area. The time units comprising this information would be as small as needed to generate an adequate account of the structural and transformational invariants that make up the event, as determined by the circumstances of the investiga- 
tion. Abstract interpretive information could also be part of $U$ to the extent it is well linked to the realities of the emergent event.

Note that the notion of such a $U$ is not so far fetched as it may at first seem. Consider a group of observers who watch an event and discuss it as exhaustively as possible. To the extent such material approximates a complete account of everything that might be said about the event from a particular cultural/historical perspective, at a relatively how level of abstraction, then it approximates $U$. Of course, in most events of everyday life, $U$ exists only in principle and the client's perception of the event, the realized affordance structure (E), is a subset of U. (The other's perception of the event would also be part of $U$ but would be entirely hypothetical except when the other is available to the therapy.) For reasons outlined above, $E$ will seldom even approximate $U$ in the natural course of an individual's awareness; even those who are highly trained can scarcely grasp simultaneously the perceptions of both self and other as they unfold, without considerable post hoc reflection.

$\mathrm{E}$ is interpreted and its meaning transformed in time by subsequent acts of recollection $\left(R_{m}\right)$. Each rccollection may, or may not, capture some informational aspect of $E$, or a previous $R_{m}$ (cf. Bartlett, 1932). As with $E$ in relation to $U$, a given $R_{m}$ would rarely be equivalent to $E$, and rarely would a $R_{m+1}$ be equivalent to $R_{m}$. Interpersonal events are inherently difficult to specify in a definitive fashion and few events in our lives are subjected to extensive scrutiny. Therefore, these successive nonequivalencies make it difficult to identify $E$ with precision. Indeed, each $R_{m}$ emergent in psychotherapy - which can be designated as $\mathrm{RT}_{1}$ (recollection in therapy) in recognition of its special statusdirectly represents information of three types relative to $\mathrm{E}$ : (a) information directly given at the time of the event and that represents a subset of $\mathrm{E}$; (b) information implicationally related to $R T_{1}$, be it linguistic or episodic in nature (that is, that subset of $R T_{t}$ not intersecting $\mathrm{E}$ ); (c) if $\mathrm{m}>1$ and/or $\mathrm{t}>1$, the intersection of the current $\mathrm{RT}_{\mathrm{t}}$ with all previous $R_{m}$ and $R_{T}$.

An important implication of this line of thought is that there is considerable complexity involved in the accretion of information about $\mathrm{E}$ over time, both in terms of private recollections and those discussed with others, including discussions in psychotherapy. Set notation, using the concepts of intersection $(\cap)$, union $(U)$, and negation $(\sim)$ (see Kerlinger, 1986), vividly illustrates this complexity even with minimal assumptions about successive information intersections between recollections. Each $\mathrm{R}$ consists of a portion that directly maps $\mathrm{E}$ (i.e., $\mathrm{R} \cap \mathrm{E}$ ), and a portion that does not directly map $\mathrm{E}$ (i.e., $\mathrm{R} \cap$ $\sim \mathrm{E}$; in words: "R intersection not-E."). Similarly, each successive $\mathrm{R}$ maps some portion of each previous $\mathrm{R}$ as well as potentially offering something completely new. Thus, as just described, the remembrance of an event might look like this:

$$
\begin{gathered}
\mathrm{R}_{1}=\left(\mathrm{R}_{1} \cap \mathrm{E}\right) \cup\left(\mathrm{R}_{1} \cap \sim \mathrm{E}\right) ; \\
\mathrm{R}_{2}=\left(\mathrm{R}_{2} \cap\left(\mathrm{E} \cup \mathrm{R}_{1}\right)\right) \cup\left(\mathrm{R}_{2} \cap \sim\left(\mathrm{E} \cup \mathrm{R}_{1}\right)\right) ; \\
\mathrm{RT}_{1}=\left(\mathrm{RT}_{1} \cap\left(\mathrm{E} \cup \mathrm{R}_{1} \cup \mathrm{R}_{2}\right)\right) \cup\left(\mathrm{RT}_{1} \cap \sim\left(\mathrm{E} \cup \mathrm{R}_{1} \cup \mathrm{R}_{2}\right)\right)
\end{gathered}
$$

More generally, for a current recollection in a therapy session $\left(\mathrm{R}^{\mathrm{T}} \mathrm{T}_{1}\right)$ with $m$ previous everyday recollection events and $t-1$ previous recollection events in therapy:

$$
\begin{gathered}
R T_{1}=\left(R T_{1} \cap\left(E \cup R_{1} \cup R_{2} \cup \ldots \cup R_{m} \cup R T_{1} \cup R T_{2} \cup \ldots \cup R T_{t-1}\right)\right) \\
\cup\left(R T_{1} \cap \sim\left(E \cup R_{1} \cup R_{2} \cup \ldots \cup R_{m} \cup R T_{1} \cup R T_{2} \cup \ldots \cup R T_{t-1}\right)\right)
\end{gathered}
$$

In specific circumstances, if successive recollections did not interlink so neatly as represented here, the complexity of the description might further increase. The impacts of 
these various intersections are impossible to discern in detail even with small $m$ 's and $t^{\prime} s$. Nonetheless, they can affect current recollections in unknown ways that may be important to the work (e.g., as can be readily observed with clients who have already extensively analyzed a memory using various theories and/or who have participated in numerous previous theory-driven therapy sessions). It is easy to stray away from the informational foundation of $\mathrm{E}$, especially given the common interpersonal goal of discussing $\mathrm{E}$ in a fashion that is socially acceptable, as defined within the situation of producing the narrative. By implication, an important goal for cognitive-interpersonal therapy is not only to expand the extent to which a current $\mathrm{RT}_{\mathrm{t}}$ accurately maps $\mathrm{E}$ but also to distinguish this informational intersection from intersections with other $R_{m}$ and $R T_{t}$ - in effect to distinguish direct perceptions from interpretations of direct perceptions and interpretations of interpretations (cf. Sullivan, 1953, on the symbol-sign distinction). In so doing, the intent is to help the client become aware of how the perceived event relates to a current understanding of self that has been developing over a lifetime of direct experience of self and others.

Additionally, it may be desirable to improve the extent to which subsequent $R_{m}$ and $R T_{t}$ map both $E$ and $U$, as opposed to adding new information. As presented in the set equation above, we are assuming that each successive $R_{m}$ or $R T_{t}$ maps some aspect of $U$. Obviously, this need not be the case in that new interpretations of recollected events can reflect associations to other events, in which case R's might overlap the boundaries of U, relating to U's associated with other events. One advantage of this set theoretical formalization is that it reveals the potential for such ambiguity in references to real events.

\section{CLINICAL APPLICATIONS}

This approach is a heuristic for clinical investigation of interpersonal memories. When an event meriting analysis comes up in therapy, the problem is one of mapping the various components of the narrative report onto the model, thereby organizing them, discovering gaps, and identifying their concrete meaning and source. Technically, this is similar to approaches described by Greenberg and Safran (1981) and Toukmanian (1986) in which the clinician, via a focused interview, pursues perceptual level detail. Here, however, we also present an organizing framework as a guide to the type of information to be pursued. This involves: (a) specific inquiry into the physical/temporal event boundaries; (b) establishing the sequence of any mentioned sub-events; (c) establishing how descriptive words or phrases used in the communication with the therapist are related to directly perceived, low level, event information (E) or to later recollections and interpretations of the event $\left(\mathrm{R}_{\mathrm{m}}\right)$; (d) identifying any important $\mathrm{R}_{\mathrm{m}}$ (or $\mathrm{RT}_{t}$ ) as events in their own right that might influence the ways the client interprets the event; (e) developing concrete narrative descriptions of the physical and subjective presences of the client and other in relatively small temporal units, thereby approximating, the realized and potential affordance structure of the event; (f) developing an understanding how material selected in presenting the narrative relates to current interpersonal relationships and situations.

To these ends, it is important to guide the client to talk in terms of what was seen, heard, and felt; to conceive of the event as a real time sequence and to identify the personally relevant beginning and end even though they may not be obvious at first; to become aware of thoughts and feelings that occurred after the event that might be important in understanding it in the therapy; to describe elements of the sequence, emphasizing self, other, and context, in perceptual level terminology. Furthermore, client and therapist collaborate to specify the potential affordance structure of the event in concrete terms (including things that might have been but were not directly perceived by the client). A 
major part of this involves speculation about what the other might have been experiencing in the context of his/her immediate and extended past and future.

It should be emphasized that his approach is much more focused on the concrete perceptual underpinnings and limits of interpersonal events, on identifying how perceptual detail is mapped into verbal narratives, and on how narratives arc gencrated and transformed in an ongoing interpersonal context, than are most accounts of clinical inquiry (e.g., MacKinnon \& Michels, 1971; Sullivan, 1954). Clinicians often accept information, especially about seemingly concrete detail, as initially given in a narrative without pursuing perceptual level detail-particularly without seeking greater clarity about exactly how a person or object was perceived in the time stream. Furthermore, even when the realized affordance structure of the event is described by especially verbal clients, the potential affordance structure, including the perceptions of the other, is often ignored or taken as given without rigorous inquiry. Our experience shows that perceptual detail can be actively pursued without disrupting the therapeutic alliance-nor even a client-centered approach, for that matter (see also Rice, 1984)-and that doing so in conjunction with active, open attempts to model the real time circumstances of the event, actually enhances the relationship. Such an approach can also increase the clarity of ultimate event recall and description, the client's recognition of linkages to other relevant material, and the client's understanding of more general identifications of schema, interpersonal style, and associations to current concerns. Thus, the model points to interpersonal information directly germane to the client's own attempts to generate a personally realistic narrative in the therapy, that is, at the same time, highly relevant to the clinician's case formulation, including formulations bearing on transference and countertransference issues.

Once reasonably clear information is obtained, clinician and client can work together to analyze the plausibility of various interpretations with respect to the directly perceived event (E), the surrounding potential affordance structure (U), and the source of the interpretation (e.g., interpretations coming from self, friends, a particular perspective, and so on). Interpretations can be evaluated against a detailed data source clearly grounded in the client's own experience. The ways the interpretations themselves were constructed can be evaluated and placed in life context (e.g., more general interpersonal themes). But, perhaps most powerfully, the clinician can hypothesize with the client about details of the model not necessarily accessible in the recollected data that may inform how the event unfolded (e.g., the subjective experience of the other, or the manner in which a systems level phenomenon was operating in time). This way, clients often recognize how they have misconstrued an event (e.g., the intention of the other) more quickly than if we had not engaged with them in speculation about what the other person might have been perceiving.

\section{Case Illustrations}

The cases that follow are intended only to illustrate our current thinking about how this model might be applied, in reasonable fashion, to the investigation of clinically relevant interpersonal memories. They should not be considered confirmatory of the model, nor definitive from a technical standpoint.

In the first case, careful explorations of subunits of an event reveals how an existing interpretation is misleading the individual, thereby facilitating a discussion of links to interpersonal themes from the past.

A 28-year-old professional woman sought therapy because she felt "over-reactive and out of control." In her eighth session, she recollected an incident that she felt illustrated her over 
reactivity. A few days previously she had received notice that her supervisor was displeased with her handling of a crisis at work and wanted to meet with her. She recalled becoming "extremely anxious even though I knew I handled the crisis well." She called a friend, but felt frustrated after the call: her friend could be critical and patronizing and their talk had not helped. When she met with the supervisor, she was calm, but could recall little of the conversation. Immediately after the meeting she felt "restless, dependent, irritable, spacey," a condition that persisted for two days during which she frantically cleaned house.

The therapist, in following the model, asked the client to conceptualize the sequence of the event as if it were a videotape. The "tape" began with the details of the notification of a meeting with the supervisor. This came by phone, in the context of a flurry of conversation among office staff about the crisis. His expression of unhappiness with the events of the crisis (an affordance) was directly perceived to be displeasure with the client's performance. She described her anxiety on receipt of this message and her "restlessness, pacing, sweaty palms, racing heartbeat, and a sense of numbness and confusion."

She was then invited to hear the words of her conversation with her friend and to experience the sound of her friend's voice and her reaction to it. She recollected feeling unsupported as her friend offered a view of the crisis. She recalled feeling that she wanted to please her friend at the same time she was angry with her. Following the phone conversation, she paced around the room rehearsing possible responses to the supervisor's criticism. As she came to the beginning of the meeting, she stated that she could not recall anything of the next 20 minutes.

The therapist asked what the event was like in terms of low level perceptual detail, like what she saw, the way the room looked, and so on. The client readily recollected entering the room, shaking hands with her supervisor, where each sat, the color of his tie, and that he took notes. In so doing, she suddenly became aware of what he had said, recognizing immediately that he had not been angry with her at all but rather concerned with misinformation he had received from another source. He concluded that she had handled the situation well. She wondered aloud why she had not remembered this conversation, and thereafter her hesitancy about recollecting the situation disappeared.

She drove home intending to be with her spouse, but instead she avoided him by cleaning and doing laundry. As she described this, she became visibly anxious. The therapist asked, "Has there ever been another time you have felt like this?" Her response was immediate and animated: "Oh yes! Fvery time my father heat me." This led to an extended and very open discussion of times her mother accused her of doing something wrong, of how she handled her father's severe physical discipline, and of how she often cleaned and did chores trying to win her mother's comfort and forgiveness. She readily recognized the link between the supervisor, family events, and feelings she had on occasion in the therapy. This understanding made her feel less "crazy" and anxious and she began to examine her "overreactions" in the context of her prior interpersonal learning

In this example, the pursuit of low level perceptual detail of a temporally proximal interpersonal event facilitated the opening up of what could have been a highly ambiguous clinical situation, thus revealing a characteristic way of responding to a particular event configuration. We have found this often to be the case, even when complete details of the model are not pursued exhaustively. Table 1 shows how the subunits of this event can be organized in terms of the model. The entries in the Table represent an attempt to be as concrete and perceptual as possible (within the confines of space). Obviously the information could be pursued in much greater detail. Usually, however, even incomplete information moves the narrative forward. As Table 1 shows, recollections are often inconsistent with plausible representations of the interaction, and comprehending the event involves the unfulfilled wish for comfort from the friend, and later her spouse, and the unrecollected praise from the supervisor, both of which require a different interpretation of the interaction than the client had previously developed. In turn, similar themes could be examined in the relationship with the therapist. The model makes clear what is and is 


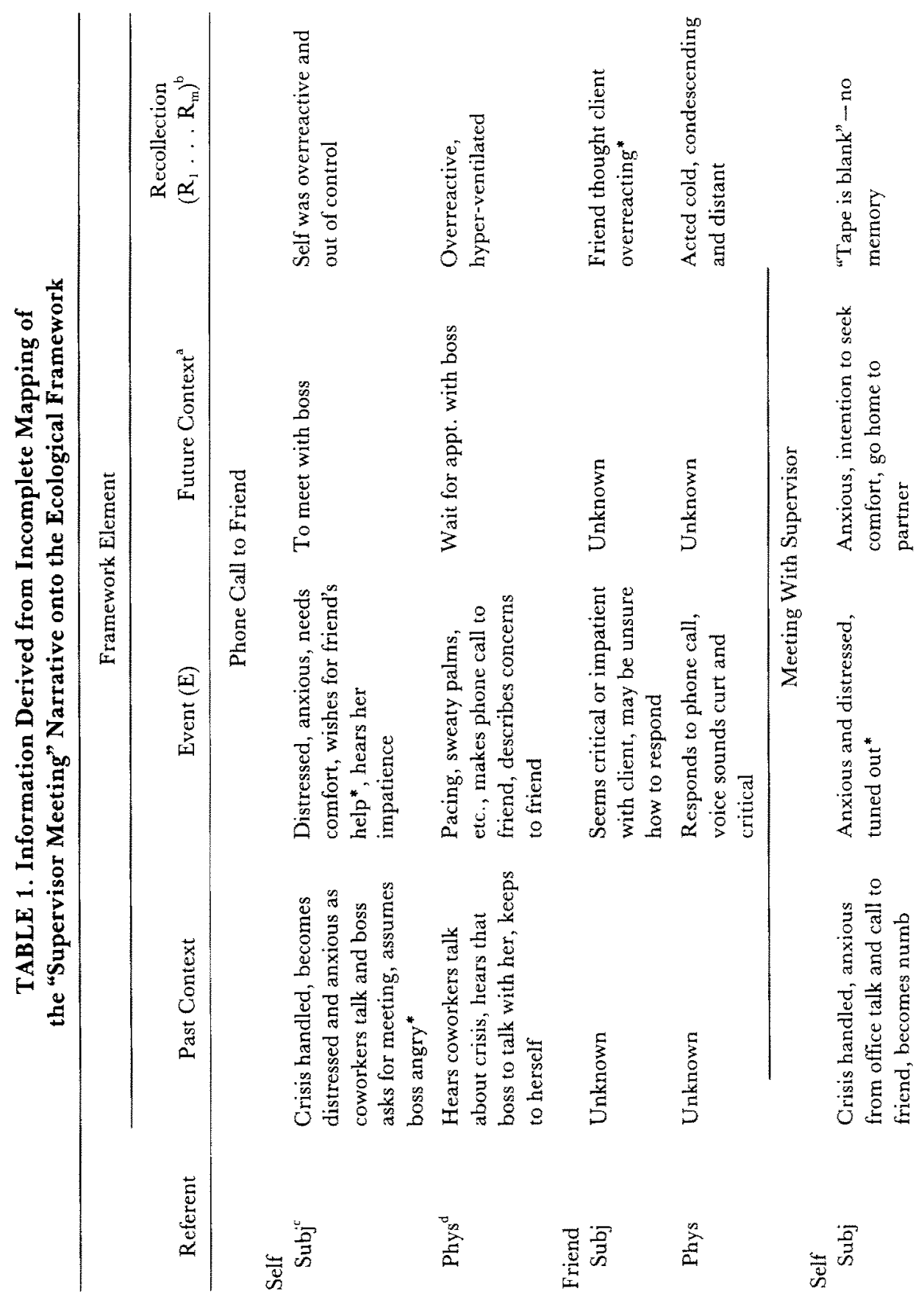



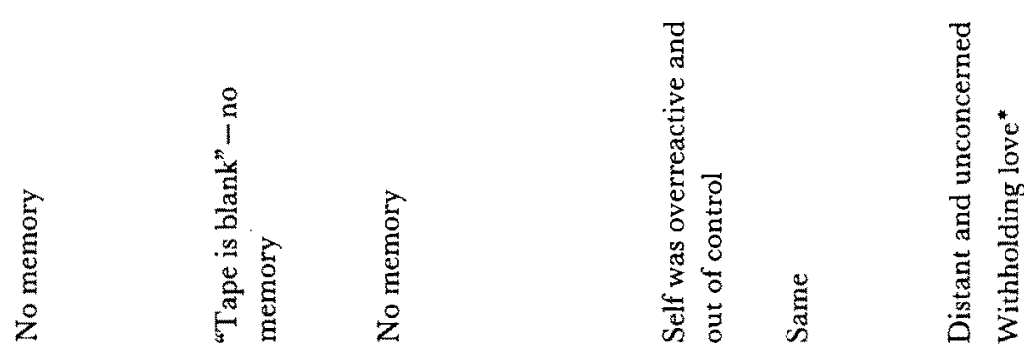

.
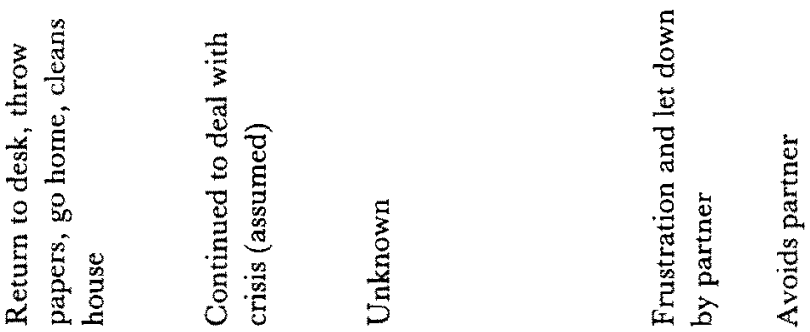

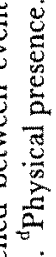

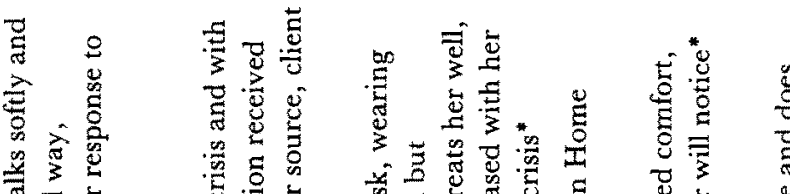

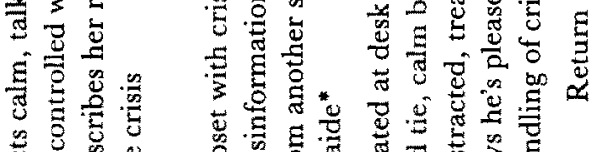

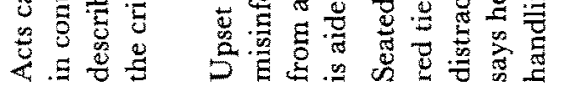

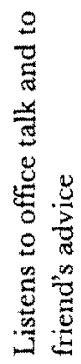

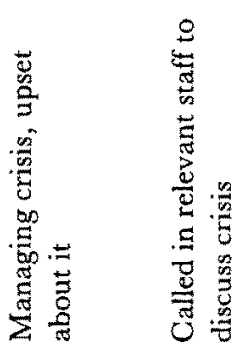

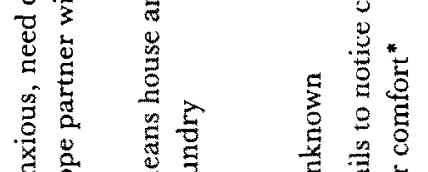

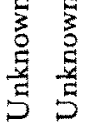

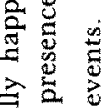

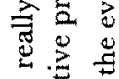

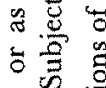

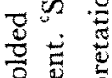
吉

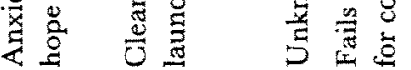
范

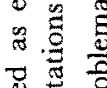
苛莺

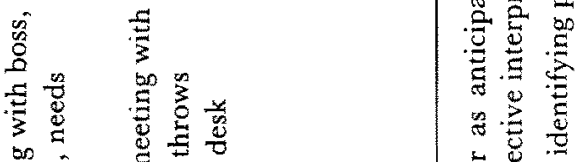

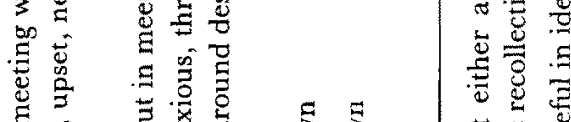

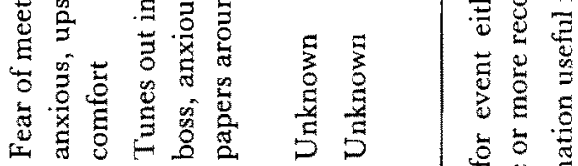

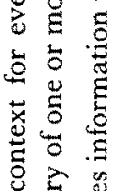

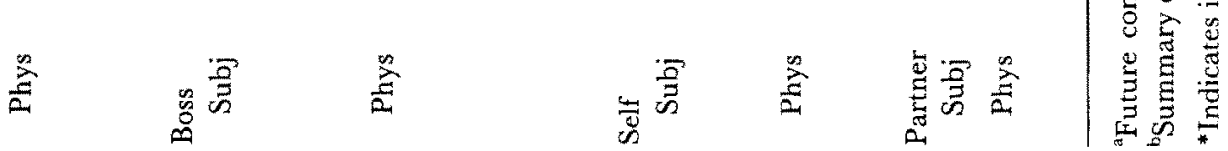


not known, revealing precisely how information is assumed in recollection $(R T$, that may not be accurate (Bonanno, 1990; Safran \& Segal, 1990).

In the following illustration, secondary recollections and accompanying interpretations $\left(R_{m}\right.$ and $\left.R T_{t}\right)$ led the client away from the interpersonal implications of an experience.

A woman, with history of episodes of depression, described a recent event that seemed related to her current depressed and anxious mood. Depression, confusion, and "craziness" had pervaded her week. These feelings were accompanied by disrupted sleep and fears that she was getting ill and would require hospitalization. These feelings began midweek, during an evening at her new boyfriend's house. She was uncertain where the relationship was going, but could identify nothing in particular that had precipitated her ill feelings. The therapist noted that she seemed generally concerned about her current condition (an example of an interpretive recollection $\left(\mathrm{R}_{\mathrm{m}}\right)$, and she could see nothing about her interactions that was relevant.

Nonetheless, she agreed to examine the onset of the feelings in greater detail (i.e., to explore $\mathrm{E}$ as distinguished from $\mathrm{R}_{\mathrm{m}}$ ). The event of visiting the boyfriend was conceptualized in terms of Fig. 1. She was asked to describe in detail getting to the boyfriend's house with particular attention to what she saw and felt. She described getting to the house very late and being disappointed that the promised dinner was still in the early stages of preparation. She was very hungry, but excited enough about the visit that she ignored the inconvenience. She described entering the kitchen and sitting at the table while the boyfriend proceeded with the preparations. At this point, she recalled having fears about her mental health and intrusive thoughts about hospitalization. These thoughts seemed related to her depression: The boyfriend seemed light and happy, and this made it seem all the more likely that she was "crazy." As she became increasingly anxious, the therapist gently asked that she recollect the event in even greater detail by describing what she looked at as she sat at the table. She described looking at the clock and noting the late hour, noting her hunger again, then watching her boyfriend preparing a stirfry. The therapist asked what she saw. The client said, "cauliflower." As she did so, she smiled recognizing that as she looked at the cauliflower (an affordance) she had experienced surprise; it was not something she would put in a stirfry. She recalled fading out of the conversation and ruminating about how different the boyfriend was, asking herself what she was doing with him, and was she making a correct choicc. How could she make correct choices given her history depression and unsatisfying relationships, and would this lead her back into a depression and the hospital?

This material led directly to a discussion of how this boyfriend fit into her ongoing concerns about relationships and her uncertainty about her judgment in these matters. These concerns were explored over the next several sessions and linked to further details in her interactions with men and to already explored information about traumatic experiences ycars earlier.

In both of these cases, the exploration of perceptual detail and interpersonal cuntext, moved the client beyond self-limiting narratives about feeling crazy toward an active exploration of issues in relationships. This happened readily as the therapist pursued the model. We could elaborate numerous additional examples in which an ambiguous therapeutic moment is clarified by careful examination of the affordance structure of an event, including events in the therapy itself. We have found the model useful for the exploration of temporally remote memories, which individuals often experience with perceptual qualities, as has been well documented (e.g., Bartlett, 1932); for elaboration of proximal and distal memories that emerge in couples and family treatment; and for assisting the process of understanding descriptions of highly emotionally charged events in a client's current life, such as angry fights between parents and children.

Finally, although it is often difficult for individuals to recollect specific incidents of recollecting remote events (recollecting recollections), it is important to examine the 
influence of these secondary episodes, such as they are available, on later recollections in therapy. For example, in the case of the young man spilling the can of paint in the pickup truck, outlined above, exploration of prior discussions with friends about the incident revealed how some of his current views of his father were constrained by views expressed by his friends about their own fathers. This facilitated an examination of a plausible representation of the father's perspective in the paint can event that, in turn, led to a discussion of how the young man's own frequent, noncompliant attitude might have played a role both in the event and in more current relationships.

\section{DISCUSSION}

We present a framework for inquiry into the ecological foundations of specific interpersonal memories. It outlines a thought experiment to be conducted each time an interpersonal memory comes up in therapy. We argue that the results of such an inquiry provide a strong database from which to conduct cognitive-interpersonal psychotherapy in the tradition of clinical theorists such as Sullivan and Carson. Such information is particularly compatible with therapies that investigate problematic interpersonal schema (e.g., Greenberg \& Safran, 1981; Rice, 1984; Safran \& Segal, 1990), problematic configurations of interpersonal experience such as nuclear scripts (see Bonanno, 1990), and narrative schema (Russell \& van den Broek, 1992).

\section{Empirical Support: What About the Fallibility of Memory?}

It is important to note that all the well-documented problems of autobiographical memory pertain to this approach (e.g., Loftus, 1993; Ross \& Conway, 1986). Applying the model offers no insurance, in itself, that the understanding of events so obtained is definitive from some external standpoint. Rather, the framework is a cueing device that invites inquiry into the perceptual specifics relevant to an interpersonal interaction and that focuses reconstructive processes on the low level episodic elements of memory (see Brewer, 1986). Obviously, there remains considerable ambiguity and uncertainty in this process. Still, the promise of this approach lies in the fact that the inquiry is guided by an adequate reference model, rather than the implicit understandings of a particular clinician. Also, as mentioned earlier, evidence is emerging that some of the problems with memory inquiry may be overstated, being more a function of inadequate memory investigation strategies than problems in remembering. For example, guided memory practices (e.g., Geiselman, Fisher, MacKinnon, \& Holland, 1985; McCloskey \& Zaragoza, 1985), even less focused than our proposal, enhance accuracy of remembered detail in eyewitness situations. Research will be needed to clarify this problem in psychotherapeutic contexts. Until then, our experience suggests the approach facilitates the inquiry as evidenced in: (a) new details that are cued, (b) the emergence and discussion of new events that contribute to the larger narrative within which specific events are nested (Neisser, 1986), (c) the readiness with which clients accept alternative views consistent with the data, and with which they expand the account, and (d) the effectiveness of interpretations of the impacts of interpersonal style in the context of such grounded data.

Indirect empirical support for the assumptions underlying the model lie in three general categories. First, Gibsonian perception theory is based in a long tradition of experimental work and successful applications in domains such as aviation (Gibson, 1979, 1986; Reed, 1988) and, more recently, to research in social perception (e..g, Ginsburg \& Smith, 1993; Valenti \& Good, 1991; Van Acker \& Valenti, 1989). Second, the representation is consistent with current views of naturalistic memory (e.g., Cohen, 1989). The notion that memories map events having a clear beginning and end points is well established in 
experimental studies. Third, recent work in social cognition (see also Westen, 1991) is relevant including work on category accessibility (Srull \& Wyer, 1980), on-line cognition (Bassili, 1989), and content-specificity in social cognition (Smith, 1990).

\section{Implications}

Several caveats are in order. Memory inquiry is not all there is to cognitive-interpersonal therapy. There are numerous surrounding issues that have not been addressed herein, such as how to select memories for extensive analysis, how to develop schematic interpretations for mapping onto memory data, and so on. This framework is intended only to encourage clinicians to pursue temporally organized perceptual information rigorously in their inquiry (cf. Brack, Brack, \& Zucker, 1992). Also, we wish to reiterate that our case illustrations should not be taken to imply strong confirmation of the model, nor that the approach we have developed thus far always yields dramatic results. As in all therapeutic endeavors, much depends on the therapeutic relationship and the skill of the therapist in developing and maintaining a productive alliance with the client.

Loftus' (1993) concerns about the authenticity of some memory narratives in psychotherapy merit special comment in light of this model. Our model is essentially constructionist (e.g., Gergen, 1985): it is an explicit framework for exploring what clients know, or think they know, and for constructing narratives that take this knowledge into account in as comprehensive a fashion as possible. However, as is implied throughout this article, an active constructive process should not be confused with an epistemological position that denies the existence of some reality external to a particular observer. We believe that there are ecological foundations for many (not all) of the important memory narratives arising in the course of psychotherapy; in this sense our philosophical position is more akin to Gibson's (see Reed, 1988), or in recent philosophy, Bhaskar (1978), or Manicas and Secord (1983). Still, there is no way of knowing whether a particular narrative is definitive when viewed from some external perspective or in light of some other ideal standard. Questions about the extent to which we attain the ideal in a particular inquiry, to which it is indeed attainable, and to which such narratives prove to be clinically useful, cannot be answered within the model itself. By the same token, our formulation should not be considered a solution to the problems being examined in the eyewitness memory literature, where an essential interpersonal context for framing the narrative is the courts -including the narrative testimony produced by a therapist referencing the content of a previous conversation with a client about an event in the client's past. Research will be needed to clarify these issues.

The problem of accuracy in memory narratives is not simple for clinicians. It is a matter of relative plausibility and relevance of a particular narrative formulation, to both client and therapist, within the context of the therapeutic relationship. Knowing detail, in itself, is no assurance of an accurate portrayal. But not using focused inquiry to examine detail and its relationship to the larger stream of interpersonal experience, virtually assures that understanding is limited. If, as Loftus discusses, an abuse memory comes into being primarily as a function of reading a book, then knowing that the event of reading is an important part of the narrative being told is essential to understanding the telling. This would be true whether or not the abuse event referenced is true, by some ultimate standard. In this view, all memory narratives, and particularly those of a dramatic nature, involve distinct interpersonal circumstances that are important to the treatment.

Our model, and evidence for the state dependency of memory (Bower, 1981), suggest that the attitude of the clinician is important to all memory inquiry. Steps should be taken to avoid premature foreclosure on the examination of an event and the variety of ways it 
might be experienced by a client. An important advantage of an emphasis on the affordance structure of the event - as it is remembered and described in the context of an affordance structure existing in a therapeutic interaction - is that it helps communicate to clients the importance of their own sense of the reality of their experience in the past and in the present. In our view, this stance is both critical to successful implementation of the model, and consistent with the current research concerning memory.

Despite these concerns, therapists who follow the model may be able to develop more grounded and comprehensive interpretations of remembered events (e.g., Bucci, 1989). In so doing, particular perspectives on the events are likely to be seen as more plausible than others, within the context of the therapeutic relationship. Nonetheless, clinicians need to remain cautious in communicating certainty about memory narratives even in the advanced stages of a therapy. Our model suggests that such assertions are powerful interventions that could inappropriately constrain the development of a more complete understanding of the referenced events. Therefore, they should be treated with as much care as any clinical intervention. At the same time, this caution needs to be balanced by appropriate respect for the client's own sense of the authenticity of personal experience. If a client chooses to view a memory as meaning something particular for her life, or as having been repressed, then the interpersonal consequences of this belief, which can be substantial, car be addressed in the therapy even though there is no formal way for a clinician to establish the definitive meaning, or fact of the repression, one way or the other. We have discovered that situations wherein psychological defenses seem to be operative, can often be seen in terms of more benign attention and selection processes in narrative construction when the complete temporal context of the event is carefully considered. Research will be required to determine if this approach actually is useful in ruling out the repression hypothesis.

\section{CONCLUSION}

This approach facilitates the overarching goal in interpersonal therapy of uncovering and working with interpersonal patterns emergent within the therapeutic relationship (e.g., Carson, 1969; Kiesler, 1982; Safran \& Segal, 1990; Singer, 1988). Problematic aspects of therapeutic interactions often disappear as the client feels more understood and in control of the information of his or her past. In turn, more central, transferential aspects of these interactions are revealed in sharp relief, and more specific information is available to the clinician to reference these hidden aspects of interpersonal style.

Several areas of research are suggested by the model, including studies of real time interpersonal perceptions and their transformation later in memory, studies of the effects of training in the use of the model on memory narratives referencing independently verifiable events, and studies of the implicit frameworks governing memory inquiry already in use in the psychotherapy community.

It is quite likely that many therapists already do something like this in their memory inquiries. For them, this model offers one comprehensive framework for understanding that work, and, in particular, for reminding them about what they can and cannot know of the material experience of their clients. For others, this model provides reasons for seeking greater perceptual detail in memory narratives that are consistent with recent thinking about narrative (c.g., Russcll \& van den Broek, 1992), social construction processes (e.g., Mahoney, 1991), and even the construction of time in memory (Brack, Brack, \& Zucker, 1992; Friedman, 1993). We believe that more such models are needed in the clinical literature, bridging the gap between inadequate notions of objectivity and beliefs about the complete fluidity of social construction. Additionally, the model can be 
thought of as one conceptual guide for therapists who wish to improve the evidentiary basis of their work. Trierweiler and Stricker (1991) have called such evidence based inquiry, which attempts to approximate the fundamental details of local circumstances, local clinical science. We believe that clinical endeavors will be improved when all therapists become clearer about the evidence supporting clinical formulations, however fallible it might be. This approach to psychotherapeutic memories offers one means by which this can be accomplished.

Acknowledgements - Portions of this model were presented at the Fifth International Conference on Event Perception and Action at Miami University, Oxford, OH, July, 1989. We wish to thank members of the Society for Ecological Psychology, particularly Peter Pufall and Charles Lemery, for support and encouragement. We also thank Peter Carino, Theodore Ellenhorn, William Lax, Lorraine Mangione, Donna K. Nagata, Roger L. Peterson, Peter Pufall, George Stricker, and two reviewers for helpful comments on earlier versions of this manuscript.

\section{REFERENCES}

Bartlett, F. C. (1932). Remembering. Cambridge, England: Cambridge University Press.

Bassili, J. N., (Ed.) (1989). On-line cognition in person perception. Hillsdale, NJ: Erlbaum.

Berger, P. L., \& Luckman, T. (1966). The social construction of reality: A treatise on the sociology of knowledge. New York: Doubleday \& Company.

Bhaskar, R. (1978). A realist theory of science (2nd ed.). Brighton England: Harvester Press.

Bonanno, G. A. (1990). Remembering and psychotherapy. Psychotherapy, 27, 175-186.

Bower, G. H. (1981). Mood and memory. American Psychologist, 31, 129-148.

Brack, G., Brack, C. J., \& Zucker, A. (1992). Time perception and time processing as an aspect of the therapeutic process. Psychotherapy, 29, 336-343.

Brewer, W. F. (1986). What is autobiographical memory? In D. C. Rubin (Ed.), Autobiographical memory. Cambridge, Fngland: Cambridge University Press, 25-49.

Bruner, J. S. (1986). Actual minds, possible worlds. Cambridge, MA: Harvard University Press.

Bucci, W. (1989). A reconstruction of Freud's tally argument: A program for psychoanalytic research. Psychoanalytic Inquiry, 9, 249-281.

Bynum, W. R., Browne, E. J., \& Porter, R. (1981). Dictionary of the history of science. Princeton, NJ: Princeton University Press.

Carson, R. C. (1969). Interaction concepts of personality. Chicago, IL: Aldine.

Cohen, G. (1989). Memory in the real world. Hillsdale, NJ: Erlbaum.

Coyne, J. C., \& Gotlib, I. H. (1983). The role of cognition in depression: A critical appraisal. Psychological Bulletin, 94, 472-505.

Coyne, J. G., \& Gotlib, I. H. (1986). Studying the role of cognition in depression: Well-trodden paths and cul-de-sacs. Cognitive Therapy and Research, 10, 695-705.

Dickman, S., \& Sechrest, L. (1985). Research on memory and clinical practice. In G. Stricker \& R. H. Keisner (Eds.). From research to clinical practice (pp. 15-44). New York: Plenum.

Ericsson, K. A., \& Simon, H. A. (1984). Protocol analysis: Verbal reports as data. Cambridge, MA: MIT Press.

Finkelhor, D. (1979). Sexually victimized children. New York: Free Press.

Freud, S. (1989). Screen memories. In P. Gay (Ed.), The Freud reader (pp. 117-126), New York: W.W. Norton \& Co. (Original work published 1899).

Friedman, W. J. (1993). Memory for the time of past events. Psychological Bulletin, 113, 44-66.

Geiselman, R. E., Fisher, R. P., MacKinnon, D. P., \& Holland, H. L. (1985). Eyewitness memory enhancement in the police interview: Cognitive retrieval mnemonics versus hypnosis. Journal of Applied Psychology, 70, 401-412.

Gergen, K. J. (1985). The social constructionist movement in modern psychology. American Psychologist, 40, $266-275$.

Gibson, J. J. (1966). The senses considered as perceptual systems. Boston, MA: Houghton Mifflin.

Gibson, J. J. (1986). The ecological approach to visual perception. Hillsdale, NJ: Erlbaum.

Gill, M. (1982). Analysis of transference: I. Theory and technique. Psychological Issues, 53, 1-17.

Ginsburg, G. P., \& Smith, D. L. (1993). Exploration of the detectable structure of social episodes: The parsing of interaction specimens. Ecological Psychology, 5, 195-233. 
Greenberg, L. S., \& Safran, J. D. (1981). Encoding and cognitive therapy: Changing what clients attend to. Psychotherapy: Theory, research, and practice, 18, 163-169.

Guidano, V. F., \& Liotti, G. (1983). Cognitive processes and emotional disorders. New York: Guilford.

Hawking, S. W. (1988). A brief history of time. New York: Bantam Books.

Heider, F. (1958). The psychology of interpersonal relations. New York: Wiley.

Kerlinger, F. N. (1986). Foundations of behavioral research (3rd ed.). New York: I Iolt, Rinehart, \& Winston, Inc.

Kiesler, D. J. (1982). Confronting the client-therapist relationship in psychotherapy. In J. C. Anchin \& D. J. Kiesler (Eds.), Handbook of interpersonal psychotherapy (pp. 274-295). New York: Pergamon.

Klinger, E. (1978). Modes of normal conscious flow. In K. S. Pope \& J. L. Singer (Eds.), The stream of consciousness: Scientific investigations into the flow of human experience (pp. 225-258). New York: Plenum.

Loewald, H. W. (1976). Perspectives on memory. In M. M. Gill \& P. S. Holtzman (Eds.), Psychology versus metapsychology: Psychoonalytic essays in memory of George S. Klein (pp. 298-325). New York: International Universities Press.

Loftus, E. F. (1993). The reality of repressed memories. American Psychologist, 48, 518-537.

MacKinnon, R. A., \& Michels, R. (1971). The psychiatric interview in clinical practice. Philadelphia: W. B. Saunders Company.

Mahoney, M. J. (1985). Psychotherapy and human change processes. In M. J. Mahoney \& A. Freeman (Eds.), Cognition and human change processes. New York: Plenum.

Mahoney, M. J., \& Gabriel, T. J. (1987). Psychotherapy and the cognitive sciences: An evolving alliance. Journal of Cognitive Psychotherapy, 1, 39-59.

Mahoney, M. J. (1991). Human change processes: The scientific foundations of psychotherapy. New York: Basic Books.

Malpass, R. S., \& Devine, P. G. (1981). Guided memory in eyewitness testimony. Joumal of Applied Psychology, 66, 343-350.

Manicas, P. T., \& Secord, P. F. (1983). Implications for psychology of the new phiiosophy of science. American Psychologist, 38, 399-413.

Mannheim, K. (1936). Ideology and utopia. New York: Harcourt, Brace \& World.

Masson, J. M. (1984). The assault on truth: Freud's suppression of the seduction theory. New York: Farrar, Straus, \& Giroux.

McArthur, L. Z., \& Baron, R. M. (1983). Toward an ecological theory of social perception. Psychological Review, 90, 215-238.

McCloskey, M., \& Zaragoza, M. (1985). Misleading postevent information and memory for events: Arguments and evidence against memory impairment hypotheses. Joumal of Experimental Psychology: General, 114, 1-16.

Miller, G. A., \& Johnson-Laird, P. N. (1976). Language and perception. Cambridge, MA: Harvard University Press.

Neisser, U. (1976). Cognition and reality: Principles and implications of cognitive psychology. San Francisco, CA: Freeman.

Neisser, U. (1986). Nested structure in autobiographical memory. In D. C. Rubin (Ed.), Autobiographical memory (Pp. 71-81). Cambridge, England: Cambridge University Press.

Neisser, U. (1991, August). The ecological and social roots of cognition. Paper presented at the 99th Annual Convention of the American Psychological Association, San Francisco, CA.

Nelson, K. (1993). The psychological and social origins of autobiographical memory. Psychological Science, 4, 714.

Newtson, D., Engquist, G., \& Bois, J. (1977). The objective basis of behavioral units. Journal of Personality and Social Psychology, 35, 847-862.

Nisbett, R. E., \& Wilson, T. D. (1977). Telling more than we can know: Verbal reports on mental processes. Psychological Review, 84, 231-259.

Orne, M. T., Whitehouse, W. G., Dinges, D. F., \& Orne, E. C. (1988). In H. M. Pettinati (Ed.), Hypnosis and memory (pp. 21-63). New York: Guilford.

Paivio, A. (1990). Mental representations: A dual coding approach. New York: Oxford University Press.

Polkinghorne, D. E. (1988). Narrative knowing and the human sciences. Albany, NY: State University of New York Prcss.

Proust, M. (1982). Remembrance of things past (Vol. I). (C.K. Scott Moncrieff \& Terence Kilmartin, Trans.). New York: Vintage Books.

Reed, E. S. (1988). James J. Gibson and the psychology of perception. New Haven, CT: Yale University Press.

Rice, L. N. (1984). Client tasks in client-centered therapy. In R. F. Levant \& J. M. Schlien (Eds.), Client-centered therapy and the person-centered approach: New directions in theory, research, and practice. New York: Praeger.

Ross, M., \& Conway, M. (1986). Remembering one's own past: The construction of personal histories. In R. M. Sorrento \& E. T. Higgins (Eds.), Handbook of motivation and cognition (pp. 122-144). New York: Guilford. 
Runeson, S., \& Frykholm, G. (1983). Kinematic specification of dynamics as an informational basis for person-and-action perception: Expectation, gender recognition, and deceptive intention. Journal of Experimental Psychology: General, 112, 585-615.

Russell, R. L., \& van den Broek, P. (1992). Changing narrative schemas in psychotherapy. Psychotherapy, 29, 344-354.

Safran, J. D., \& Grcenberg, L. S. (1988). Fceling, thinking, and acting: A cognitive framework for psychotherapy integration. Journal of Cognitive Psychotherapy: An International Quarterly, 2, 109-131.

Safran, J. D., \& Segal, Z. V. (1990). Interpersonal process in cognitive therapy. New York: Basic Books.

Sarbin, T. R., (Ed.) (1986). Narrative psychology: The storied nature of human conduct. New York: Praeger.

Schachtel, E. G. (1949). On memory and childhood amnesia. In P. Mullahy (Ed.), A study of interpersonal relations: New contributions to psychiatry (pp. 3-49). New York: Hermitage Press.

Shaw, R. E., \& Hazelett, W. M. (1986). Schemas in cognition. In V. McCabe \& G. J. Balzano (Eds.), Event cognition: An ecological perspective (pp. 45-58). Hillsdale, NJ: Erlbaum.

Singer, J. L. (1988). Reinterpreting the transference. In D. C. Turk \& P. Salovey (Eds.), Reasoning, inference, and judgment in clinical psychology (pp. 182-205). New York: The Free Press.

Smith, E. R. (1990). Content and process specificity in the effects of prior experiences. In T. K. Srull \& R. S. Wyer, Jr. (Eds.), Advances in social cognition (Vol III) (pp. 1-59). Hillsdale, NJ: Erlbaum.

Spence, D. P. (1982). Narrative truth and historical truth: Meaning and interpretation in psychoanalysis. New York: W. W. Norton.

Srull, T. K., \& Wyer, R. S. (1980). Category accessibility and social perception: Some implications for the study of person memory and interpersonal judgments. Journal of Personality and Social Psychology, 38, 841-856.

Sullivan, H. S. (1953). The interpersonal theory of psychiatry. New York: W. W. Norton.

Sullivan, H. S. (1954). The psychiatric interview. New York: W. W. Norton.

Toukmanian, S. (1986). A measure of client perceptual processing. In L. S. Greenberg \& W. Pinsoff (Eds.) The psychotherapeutic process: $A$ research handbook. New York: Guilford Press.

Trierweiler, S. J. (1984). Language extension in social cognition: Personality impression judgment as a cognitive matching operation. (Doctoral Dissertation, University of Illinois, Urbana-Champaign, 1984). Dissertation Abstracts International, $45,(1-\mathrm{B}), 407$.

Trierweiler, S. J., \& Stricker, G. (1991). The rcscarch and cvaluation competency area: Training the local clinical scientist. In R. L. Peterson, J. McHolland, R. J. Bent, E. Davis-Russell, G. E. Edwall, E. Magidson, K. Polite, D. L. Singer, \& G. Stricker (Eds.), The core curriculum in professional psychology. Washington DC: American Psychological Association \& National Council of Schools of Professional Psychology.

Turk, D. C., \& Salovey, P. (1985). Cognitive structures, cognitive processes, and cognitive-behavior modification: I. Client issues. Cognitive Therapy and Research, 9, 1-17.

Valenti, S. S., \& Good, J. M. M. (1991). Social affordances and interaction I: Introduction. Ecological Psychology, 3, 77-98.

Van Acker, R., \& Valenti, S. S. (1989). Perception of social affordances by children with mild handicapping conditions: Implications for social skills research and training. Ecological Psychology, 1, 383-405.

van der Kolk, B. (1988). The trauma spectrum: The interaction of biological and social events in the gentesis of the trauma response. Journal of Traumatic Stress, 1, 273-290.

Westen, D. (1991). Social cognition and object relations. Psychological Bulletin, 109, 429-455. 